\title{
Mortality rate in patients with nosocomial Acinetobacter meningitis from a Brazilian hospital
}

\begin{abstract}
Background: The mortality rate due to Acinetobacter baumannii nosocomial meningitis (ANM) is high. Objective: The aim of this study was to evaluate the factors that have influence over the outcomes in ANM patients. Methods: A retrospective analysis of 22 cases of ANM was conducted in a hospital with high incidence of multidrug resistance. Results: The mean age of patients was 43 years (21 to 91) and 54.5\% were male. All ANM cases occurred within 60 days of admission and the mean duration of illness was of 18.2 days. All cases were associated with previous neurosurgical procedures: elective surgery (27.2\%), external shunt (54.4\%) and emergency surgery due to trauma (18.1\%). Imipenem resistance was observed in $40.9 \%$ of cases, but ampicillin/sulbactam resistance was lower (27.2\%). The mortality rate of ANM patients was of $72.7 \%$. The only risk factor associated with mortality was inappropriate therapy within five days after CSF collection. All patients who survived the meningitis episode had received appropriate therapy, in contrast to only $69.2 \%$ of those who did not survive $(\mathrm{OR}=5.15$; $\mathrm{IC}=0.45-54.01)$. Conclusions: The high mortality rate observed in our study suggests the need for aggressive empirical treatment with addition of drugs, including intrathecal therapy, where multi-resistant $A$. baumannii is endemic.
\end{abstract}

Keywords: Acinetobacter; meningitis; Acinetobacter baumannii; neurosurgery; imipenem; ampicillin/sulbactam.

[Braz J Infect Dis 2010;14(5):437-440]@Elsevier Editora Ltda.
Authors

Felipe Francisco Tuon, $\mathrm{MD}^{1}$

Sergio R Penteado-Filho, $\mathrm{MD}^{1}$

Diogo Amarante ${ }^{2}$

Marcio A Andrade 2

Luis A Borba

${ }^{1}$ Division of Infectious and Parasitic Diseases, Hospital Universitário Evangélico de Curitiba, Curitiba, PR, Brazil.

${ }^{2}$ Division of Internal

Medicine, Hospital

Universitário Evangélico de Curitiba, Curitiba, PR, Brazil.

${ }^{3}$ Department of Neurosurgery, Hospital

Universitário Evangélico de Curitiba, Curitiba, PR, Brazil

\section{INTRODUCTION}

Acinetobacter meningitis is a rare complication following neurosurgical procedures. Currently, Acinetobacter is the second most common agent of nosocomial meningitis in some hospitals. ${ }^{1}$ The mortality rate is high and those who outlive the infectious episode usually have severe neurological deficits. ${ }^{2}$ The estimated $15 \%$ mortality rate of nosocomial meningitis ${ }^{3}$ increases to $40 \%$ if caused by Acinetobacter. ${ }^{4}$ In developing countries, it can reach up to $70 \% .^{5}$

There have been no randomized controlled studies conducted to evaluate different treatments for Acinetobacter meningitis. The current treatment regimen is based on case reports and pharmacological data.

Intrathecal therapy remains controversial due to divergent outcomes. The aim of this study was to evaluate the risk factors associated with treatment failure of nosocomial Acinetobacter meningitis in a cohort from a Brazilian hospital.

\section{METHODS}

The hospital records of 22 patients diagnosed with nosocomial Acinetobacter meningitis admitted from January 2006 to January 2009 were retrospectively reviewed. Inclusion criteria were: (i) clinical evidence of central nervous system infection, (ii) isolation of A. baumannii from cerebrospinal fluid, and (iii) acquisition of the infection more than 72 hours after hospital admission. Central nervous system infection was defined as increased white cell count $(>50 \%$ polymorphonuclear leucocytes), increased protein and/or decreased glucose $(<15 \mathrm{~g} / \mathrm{dL})$ in cerebrospinal fluid. A. baumannii identification without cerebrospinal fluid alterations was considered contamination/colonization. ${ }^{1}$

Variables abstracted from the patient record, summarized in Table 1 and 2, were: gender, age, cerebrospinal fluid (number of leukocytes $/ \mathrm{mm}^{3}$, glucose, and protein levels), history of trauma, presence of external shunt at the time of meningitis diagnosis, days of
Submitted on: 03/05/2010 Approved on: 06/21/2010

Correspondence to: Felipe Francisco Tuon Infectious and Parasitic Diseases Clinic, Hospital Universitário Evangélico de Curitiba, Alameda Augusto Stellfeld 1908, $3^{\circ}$. andar $-\mathrm{SCIH}-$ Bigorrilho, Curitiba - PR - BRAZIL.

CEP: $80730-150$

Phone: +55-41-32405055

Fax: +55-41-32405274

E-mail:

flptuon@gmail.com

We declare no conflict of interest. 
Table 1. Clinical findings and cerebrospinal characteristics of 22 patients with Acinetobacter meningitis

\begin{tabular}{|c|c|c|c|c|c|c|c|c|c|c|}
\hline Case & Age & Gender & $\begin{array}{l}\text { Leukocytes } \\
\text { (cells } / \mathrm{mm}^{3} \text { ) }\end{array}$ & $\begin{array}{c}\text { Neutrophils } \\
\text { (\%) }\end{array}$ & $\begin{array}{c}\text { Lymphocytes } \\
\text { (\%) }\end{array}$ & $\begin{array}{l}\text { Glucose } \\
\text { (mg/dL) }\end{array}$ & $\begin{array}{c}\text { Protein } \\
\text { (mg/dL) }\end{array}$ & Trauma & $\begin{array}{l}\text { External } \\
\text { shunt }\end{array}$ & Outcome \\
\hline$\# 1$ & 38 & $\mathrm{~F}$ & 1536 & 89 & 11 & 2 & 1258 & $\mathrm{~N}$ & $\mathrm{~N}$ & Death \\
\hline \#2 & 45 & $\mathrm{~F}$ & 20 & 3 & 12 & 44 & 191 & $\mathrm{~N}$ & $\mathrm{Y}$ & Death \\
\hline$\# 3$ & 30 & M & 5 & 0 & 0 & 40 & 45 & $\mathrm{Y}$ & $\mathrm{N}$ & Death \\
\hline$\# 4$ & 59 & M & 410 & 100 & 0 & 17 & 352 & $\mathrm{~N}$ & Y & Death \\
\hline$\# 5$ & 38 & M & 18 & 10 & 0 & 1 & 92 & $\mathrm{~N}$ & $\mathrm{Y}$ & Death \\
\hline$\# 6$ & 21 & $\mathrm{M}$ & 69 & 10 & 84 & 45 & 41 & $\mathrm{~N}$ & $\mathrm{Y}$ & Death \\
\hline$\# 7$ & 57 & $\mathrm{~F}$ & 876 & 70 & 22 & 73 & 32 & $\mathrm{~N}$ & $\mathrm{~N}$ & Survival \\
\hline$\# 8$ & 53 & $\mathrm{~F}$ & 540 & 100 & 0 & 1 & 134 & $\mathrm{~N}$ & $\mathrm{Y}$ & Death \\
\hline$\# 9$ & 23 & $\mathrm{~F}$ & 350 & 100 & 0 & 1 & 43 & $\mathrm{~N}$ & $\mathrm{Y}$ & Death \\
\hline$\# 10$ & 39 & $\mathrm{M}$ & 35 & 85 & 13 & 55 & 33 & $\mathrm{Y}$ & $\mathrm{Y}$ & Survival \\
\hline$\# 11$ & 40 & $\mathrm{~F}$ & 53 & 44 & 56 & 101 & 94 & $\mathrm{~N}$ & $\mathrm{Y}$ & Death \\
\hline$\# 12$ & 78 & $\mathrm{M}$ & 15 & 3 & 97 & 1 & 119 & $\mathrm{~N}$ & $\mathrm{Y}$ & Death \\
\hline$\# 13$ & 38 & M & 960 & 60 & 40 & 38 & 128 & $\mathrm{~N}$ & $\mathrm{Y}$ & Survival \\
\hline$\# 14$ & 25 & M & 12800 & 96 & 4 & 1 & 590 & $\mathrm{Y}$ & $\mathrm{N}$ & Survival \\
\hline$\# 15$ & 46 & M & 150 & 42 & 54 & 43 & 37 & $\mathrm{Y}$ & $\mathrm{Y}$ & Death \\
\hline$\# 16$ & 56 & M & 683 & 79 & 19 & 2 & 161 & $\mathrm{~N}$ & $\mathrm{Y}$ & Death \\
\hline$\# 17$ & 49 & M & 890 & 89 & 11 & 55 & 315 & $\mathrm{~N}$ & $\mathrm{Y}$ & Death \\
\hline$\# 18$ & 27 & $\mathrm{~F}$ & 19 & 68 & 27 & 54 & 32 & $\mathrm{~N}$ & $\mathrm{~N}$ & Survival \\
\hline$\# 19$ & 91 & $\mathrm{~F}$ & 9300 & 98 & 2 & 13 & 722 & $\mathrm{~N}$ & $\mathrm{Y}$ & Death \\
\hline$\# 20$ & 56 & $\mathrm{M}$ & 1700 & 100 & 0 & 5 & 176 & $\mathrm{~N}$ & $\mathrm{~N}$ & Death \\
\hline$\# 21$ & 64 & $\mathrm{~F}$ & 1250 & 100 & 0 & 1 & 428 & $\mathrm{~N}$ & $\mathrm{Y}$ & Death \\
\hline$\# 22$ & 2 & $\mathrm{~F}$ & 2218 & 95 & 2 & 56 & 1844 & $\mathrm{~N}$ & $\mathrm{Y}$ & Survival \\
\hline
\end{tabular}

admission before infection and total length of hospital stay, elective surgery, previous use of antibiotics, susceptibility tests for Acinetobacter, antibiotic therapy (intravenous and intrathecal) used, and patient outcome. Acinetobacter baumannii was identified using biochemical methods. Antibiotic susceptibility was assayed by diffusion disc according to CLSI. ${ }^{6}$

Appropriate therapy was defined as administration of one or more active agents against A. baumannii in adequate doses and routes of administration.

Patient outcome was deemed successful if the patient had been discharged from hospital without re-admission within the following three months. All other outcomes were considered failure.

Statistical analyses were performed using the SPSS software (version 11; Chicago, IL, USA). Distribution of variables in the surviving and non-surviving groups was assessed by $\chi^{2}$ test or Fishers exact test for categorical variables, and by the Mann-Whitney test for continuous variables. Variables significantly associated with mortality in univariate analysis will be included in a binary multivariate logistic regression model.

\section{RESULTS}

In this case study, we report 22 cases of meningitis caused by A. baumannii. The mean age of patients was 43.6 year (21 to 91 ) and $54.5 \%$ were male. Cerebrospinal fluid culture grew A. baumannii within 60 days of admission, and the mean length of hospital stay was 18.2 days. Patients and cerebrospinal characteristics are described in Table 1. Two patients were excluded due to contamination/colonization.

All cases had previous neurosurgery procedures, including elective surgery (27.3\%), external shunt (54.5\%), and emergency surgery due to trauma (18.1\%).

Antibiotic susceptibility pattern of isolated A. baumannii is described in Table 2. Susceptibility to imipenem and ampicillin/sulbactam was ascertained in 13 (59\%) and 16 (73\%) of the isolates, respectively. The fatality rate among ANM patients was of $72.7 \%$. None of the evaluated risk factors was significantly associated to patient mortality. Out of 22 patients, only 17 (77.2\%) received treatment, including two patients who received intrathecal therapy in addition to systemic antibiotics. The reason for abstaining from antimicrobial treatment in four cases was death 
Table 2. Comparison of risk factors, antibiotic susceptibilities and outcomes of 22 patients with Acinetobacter meningitis according to their survival status

\begin{tabular}{|c|c|c|c|}
\hline Variable & $\begin{array}{l}\text { Survived } \\
\text { (6 cases) }\end{array}$ & $\begin{array}{c}\text { Died } \\
\text { (16 cases) }\end{array}$ & $\begin{array}{c}\text { All } \\
\text { (22 cases) }\end{array}$ \\
\hline Gender (male) & $2(50.0 \%)$ & $10(62.5 \%)$ & $12(54.5 \%)$ \\
\hline Age (Mean with Range) & $39[27-57]$ & $45.5[21-91]$ & $43[21-91]$ \\
\hline Days of admission before infection (Mean with Range) & $12[3-32]$ & 17 [3-60] & 16 [3-60] \\
\hline Total hospitalization (Mean with Range) & $50[9-115]$ & $30.5[10-96]$ & $40[9-115]$ \\
\hline Trauma & $1(16.6 \%)$ & $3(18.7 \%)$ & $4(18.1 \%)$ \\
\hline Elective surgery & $2(33.3 \%)$ & $4(25.0 \%)$ & $6(27.2 \%)$ \\
\hline After shunt & $3(50.0 \%)$ & $9(56.3 \%)$ & $12(54.5 \%)$ \\
\hline Previous antibiotic use & $3(50.0 \%)$ & $14(87.5 \%)$ & $17(77.2 \%)$ \\
\hline \multicolumn{4}{|l|}{ Antibiotic sensibility } \\
\hline Amikacin & $3(50 \%)$ & $4(25 \%)$ & $7(31.8 \%)$ \\
\hline Gentamycin & $3(50 \%)$ & $4(25 \%)$ & $7(31.8 \%)$ \\
\hline Tobramycin & $3(50 \%)$ & $6(37.5 \%)$ & $9(40.9 \%)$ \\
\hline Ampicillin/Sulbactam & $5(83.3 \%)$ & $11(68.8 \%)$ & $16(72.7 \%)$ \\
\hline Aztreonam & $2(33.3 \%)$ & $0(0 \%)$ & $2(9.1 \%)$ \\
\hline Cefepime & $3(50 \%)$ & $2(12.5 \%)$ & $5(22.7 \%)$ \\
\hline Ciprofloxacin & $3(50 \%)$ & $3(18.8 \%)$ & $6(27.3 \%)$ \\
\hline Imipenem & $5(83.3 \%)$ & $8(50.0 \%)$ & $13(59.1 \%)$ \\
\hline Meropenem & $5(83.3 \%)$ & $7(43.8 \%)$ & $12(54.5 \%)$ \\
\hline Piperacillin/Tazobactam & $3(50 \%)$ & $5(31.3 \%)$ & $8(36.4 \%)$ \\
\hline \multicolumn{4}{|l|}{ Treatment } \\
\hline Intrathecal therapy & $0(0.0 \%)$ & $2(12.5 \%)$ & $2(9.9 \%)$ \\
\hline Systemic antibiotic & $4(66.6 \%)$ & $13(81.2 \%)$ & $17(77.2 \%)$ \\
\hline Appropriate therapy according to antimicrobial resistance* & $4(100.0 \%)$ & $9(69.2 \%)$ & $13(59.0 \%)$ \\
\hline
\end{tabular}

* The percentage was calculated for all patients using systemic antibiotics.

before final culture results. Appropriate antibiotic therapy was initially administered to $100 \%$ of the surviving patients, whereas only $69 \%(9 / 16)$ of patients who did not survive received it. There was no significant difference between survivors or therapies $(\mathrm{OR}=5.15$; IC $=$ 0.45-54.01). Ventricular shunts were removed from all patients with confirmed meningitis.

\section{DISCUSSION}

The mortality rate observed in this study was high (73\%). Mortality rates ranging from $30 \%-70 \%$ have been previously reported and are generally higher in developing countries. ${ }^{4,5,7,8}$ Studies assessing the mortality rate associated with meningitis have confirmed higher mortality rates associated with Acinetobacter as compared to other Gramnegative bacilli. ${ }^{4,9}$
Treatment of A. baumannii is an issue of concern, specifically because of the increasing prevalence of carbapenem resistance and colistin and polymyxin use. In our study, treatment with carbapenem would have failed in more than $40 \%$ of cases. The reason for the failure attributed to carbapenems is not clear. A. baumannii showed increased susceptibility to sulbactam. In our hospital, all strains were routinely tested using the diffusion disc assay for polymyxin susceptibility, but this method is not reliable. Sulbactam is an effective drug against Acinetobacter, as confirmed by in vitro and in vivo studies, as well as by several clinical trials. ${ }^{10}$ However, physicians continue to avoid this drug, preferring colistin/polymyxin. Resistance to polymyxins is rare, even in a hospital with high incidence of carbapenem-resistant $P$. aeruginosa, although some cases have been published. ${ }^{11}$ 
Polymyxins penetrate the cerebrospinal fluid and produce sustained bactericidal concentrations. Intrathecal therapy further improves patient outcomes. ${ }^{12}$ Association of antibiotics have been suggested to improve patient outcome, but the literature regarding this issue is scarce. ${ }^{7,13-15}$ Rifampicin and aminoglycosides are drugs that can be used in association with polymyxins or carbapenems.

Tigecycline is a therapeutic option; however, its effectiveness for meningitis has not been studied yet. Wadi and Rub published an ANM case successfully treated with tigecycline. ${ }^{16}$ Pharmacokinetic and pharmacodynamic data indicate that tigecycline blood concentrations seem to be suboptimal for exerting maximal antibacterial activity at this compartment. Aggressive treatment of $A$. baumannii meningitis using a multidrug regimen, including intrathecal therapy, appears to be indicated. In our study, only two patients were treated with intrathecal therapy. This could be one explanation for the high mortality rate. In a recent review, intrathecal plus systemic therapy was recommended for treatment of ANM patients. ${ }^{17}$

Risk factors are important in predicting the outcomes of ANM patients. A case-control study showed a higher incidence of hydrocephaly in patients with Acinetobacter. ${ }^{8}$ Although not technically defined as a risk factor, previous colonization with Acinetobacter is thought to increase risk of developing ANM. ${ }^{18-20}$ In our institution, A. baumannii is the most common cause of ventilator-associated pneumonia and is commonly isolated from several sites in the patient.

In conclusion, Acinetobacter meningitis is a hazardous infection in neurosurgery units. Actions aiming at reducing post-surgery or shunt infection must be evaluated routinely. The high mortality rate observed in our study suggests the need for treatment with active agents against Acinetobacter, especially in settings where this microorganism is endemic. It is also recommended the addition of intrathecal therapy after identification of the bacterium. Prospective trials with intrathecal and intravenous colistin could help defining an appropriate therapy for A. baumannii meningitis.

\section{ACKNOWLEDGEMENTS}

We thank Virginia Helena Soares de Souza and Claudio Frank for their continuous care of patients in the ICU.

\section{REFERENCES}

1. Sacar S, Turgut H, Toprak $\mathrm{S}$ et al. A retrospective study of central nervous system shunt infections diagnosed in a university hospital during a 4-year period. BMC Infect Dis 2006; 6:43.

2. Erdem I, Hakan T, Ceran $\mathrm{N}$ et al. Clinical features, laboratory data, management and the risk factors that affect the mortality in patients with postoperative meningitis. Neurol India 2008; 56:433-7.

3. Streharova A, Benca J, Holeckova K et al. Comparison of postsurgical and community acquired bacterial meningitis - analysis of 372 cases within a nationwide survey. Neuro Endocrinol Lett 2007; 28(Suppl 3):7-9.
4. Huttova M, Freybergh PF, Rudinsky B et al. Postsurgical meningitis caused by Acinetobacter baumannii associated with high mortality. Neuro Endocrinol Lett 2007; 28(Suppl 2):15-6.

5. Metan G, Alp E, Aygen B, Sumerkan B. Acinetobacter baumannii meningitis in post-neurosurgical patients: clinical outcome and impact of carbapenem resistance. J Antimicrob Chemother 2007; 60:197-9.

6. CLSI. Performance Standards for Antimicrobial Susceptibility Testing; Twentieth Informational Supplement. CLSI documento M100-S20. Wayne, PA. Clinical and Laboratory Standards Institute 2010.

7. Rodriguez GA, Blanco A, Asensi V et al. Multidrug-resistant Acinetobacter meningitis in neurosurgical patients with intraventricular catheters: assessment of different treatments. J Antimicrob Chemother 2008; 61:908-13.

8. Chen SF, Chang WN, Lu CH et al. Adult Acinetobacter meningitis and its comparison with non-Acinetobacter gramnegative bacterial meningitis. Acta Neurol Taiwan 2005; 14:131-7.

9. Falagas ME, Kopterides P, Siempos II. Attributable mortality of Acinetobacter baumannii infection among critically ill patients. Clin Infect Dis 2006; 43:389-90.

10. Levin AS. Treatment of Acinetobacter spp infections. Expert Opin Pharmacother 2003; 4:1289-96.

11. Reis AO, Luz DA, Tognim MC, Sader HS, Gales AC. Polymyxin-resistant Acinetobacter spp. isolates: what is next? Emerg Infect Dis 2003; 9:1025-7.

12. Falagas ME, Bliziotis IA, Tam VH. Intraventricular or intrathecal use of polymyxins in patients with Gram-negative meningitis: a systematic review of the available evidence. Int J Antimicrob Agents 2007; 29:9-25.

13. Lee CH, Tang YF, Su LH, Chien CC, Liu JW. Antimicrobial effects of varied combinations of meropenem, sulbactam, and colistin on a multidrug-resistant Acinetobacter baumannii isolate that caused meningitis and bacteremia. Microb Drug Resist 2008; 14:233-7.

14. Fulnecky EJ, Wright D, Scheld WM, Kanawati L, Shoham S. Amikacin and colistin for treatment of Acinetobacter baumannii meningitis. J Infect 2005; 51:e249-51.

15. Gleeson T, Petersen K, Mascola J. Successful treatment of Acinetobacter meningitis with meropenem and rifampicin. J Antimicrob Chemother 2005; 56:602-3.

16. Wadi JA, Al Rub MA. Multidrug resistant Acinetobacter nosocomial meningitis treated successfully with parenteral tigecycline. Ann Saudi Med 2007; 27:456-8.

17. Kim BN, Peleg AY, Lodise TP et al. Management of meningitis due to antibiotic-resistant Acinetobacter species. Lancet Infect Dis 2009; 9:245-55.

18. Gulati S, Kapil A, Das B, Dwivedi SN, Mahapatra AK. Nosocomial infections due to Acinetobacter baumannii in a neurosurgery ICU. Neurol India 2001; 49:134-7.

19. Chen HP, Lai CH, Chan YJ et al. Clinical significance of Acinetobacter species isolated from cerebrospinal fluid. Scand J Infect Dis 2005; 37:669-75.

20. Rodriguez GA, Maradona JA, Asensi V et al. Postsurgical meningitis caused by Acinetobacter baumannii: study of 22 cases and review of the literature. Rev Clin Esp 2001; 201:497500 . 